\title{
Aspekte Van Trauma As 'n Gesondheidsprobleem
}

\author{
S. van Tonder, G.A.V., G.V.V., D.V.A., D.V.O., \\ Dipl. Ortopedies, Dipl. Intensief, Sert. Spinaalbeserings.
}

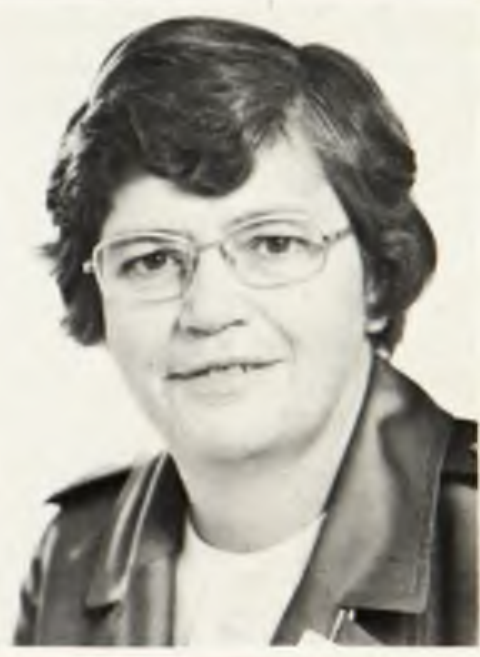

\section{SUMMARY}

Man has been subjected to trauma since the beginning of time. War exposes civilians to greater risks of injury and death than members of the armed forces. In addition to civil defence measures South Africa must increase its ability to handle trauma in peacetime and during any future national emergencies by imposing its educational and research programs in traumatology for public and professional health personnel.

Emphasis has been placed by industry on safe equipment and safety methods. The greatest exceptions in this regard are the automobile, density and diversity of traffic, and speed still leads to unprecedented numbers of accidents with many fatalities and disabilities.

Lack of adequate control in handling new toxic chemicals as well as handling of household chemicals results annually in many accidental poisonings.

Trauma continues to be the leading cause of death for people under the age of 37 years. Its causes are man-made except during natural disasters. It should to a great extent be preventable if we give it the priority and attention it deserves.

\section{INLEIDING}

$\mathbf{R}$ EG deur die menslike bestaan is die mens blootgestel aan beserings. In die moderne lewe word die voortbestaan van die mens bedreig deur die meganisering van die industrieë, die ontwikkeling van toksiese chemikalië, die ontdekking en gebruikmaking van ontvlambare sintetiese materiale en klerasie en meubels, gebruik van plastiek vir huishoudelike doeleindes en die ontwikkeling van wapens vir massa-vernietiging en uitroeiing van volkere.

Wêreldwyd en op talle gebiede is daar al navorsingsrade en -komitees in die lewe geroep wat navorsing doen oor trauma. Tog sien baie van hierdie rade trauma as die verwaarloosde siekte van die moderne gemeenskap. Van owerheidsweë moet meer aandag aan hierdie saak gegee word, navorsing moet gedoen word en opleiding moet verbeter word wat sal lei tot beter behandeling en rehabilitasie van alle indiwiduele beseerdes.
Om die getal beserings soos dit tans voorkom en om die ernstigheidsgraad daarvan te verminder asook om die gevolge daarvan te verbeter bly steeds die gesondheidsprobleem waaraan die minste aandag gegee word

Alhoewel baie chirurgiese en nou verwante dissiplines wat met trauma gemoeid is groot vordering toon, word min vordering op die voorkoming van trauma gevind, met die gevolg dat miljoene mense jaarliks onnodig beseer word.

Die rede waarom die trauma-gebied van belang is, is die eindresultate. Dit is die verliese wat aangetoon word op die gemeenskap se balansstaat, die spesifieke aantal mense wat beseer word, op spesifieke maniere, met spesifieke gevolge, benadeling of verswakking en die totale gevolglike onkoste uit menslike en ander bronne. Die gevolg is dus dat die enigste logiese kriteria vir sukses op die trauma-gebied is om die omvang en verliese as gevolg van beserings te verminder.

$\mathrm{Na}$ talle ondersoeke en navorsing wat in verskeie lande gedoen is, is bevind dat die mees algemene oorsaak van 
beserings motorongelukke is. Maar daar is ook baie ander oorsake van beserings soos byvoorbeeld ongelukke by die huis, sport, alkohol, aanrandings en beserings wat by die werk en op straat opgedoen word. Baie van hierdie ongelukke is voorkombaar en daar word aanbeveel dat groot publisiteitsveldtogte van stapel gestuur moet word om die publiek bewus te maak van gevaar-areas tuis, by die werk, op die speelgrond en op straat.

\section{Oorloë}

Sedert die ontstaan van die Oos-Wes magsblokke, het daar 'n geweldige wapenwedloop begin. Die Westerse lande moet voortdurend hul demokratiese vryheid beskerm teen die dreigende oorheersing van 'n kommunistiese diktatuur. So beleef Suid-Afrika ook hierdie bedreiging nie net op sy landsgrense nie maar ook midde in die gemeenskap dreig die gevare.

Oorloë kan gesien word as trauma-epidemies. Met die wêreldwye bedreiging van oorloë het navorsing op die gebied van trauma nou 'n noodsaaklikheid geword. Trauma soos dit voorkom in oorloë maar ook soos dit in die algemene lewensbestaan van die mens voorkom. Soos oorloë vandag gevoer word is dit nie net die militêre personeel op die slagveld wat in gevaar is nie, maar ook die gemeenskap wat beskerm word. Daar is 'n steeds groeiende gewaarwording dat die gemeenskap in die hedendaagse oorloë meer blootgestel is aan beserings en sterftes as die militêre geledere.

Die gevaar van die beskikbaarheid van enige wapens aan die mens lê daarin dat dit alleenlik 'n geval is van tyd en omstandighede voordat hierdie wapens gebruik word. Wêreldwyd word daar pogings aangewend om die atomiese wapens te verbied, maar navorsing op hierdie gebied gaan nog steeds voort.

Die belangrikste ongevalle wat voorkom by kernwapens is brandwonde wat gepaard gaan met verskillende grade ioniseringsbestraling. Daar is baie min mediese navorsing op hierdie gebied gedoen. Om swaar metaal beskermende klere te ontwerp as beskerming teen bestraling sal nie vir die publiek aanvaarbaar wees nie. Dit mag dalk moontlik wees om met metaalskilde slegs sekere areas van die menslike liggaam te beskerm, soos byvoorbeeld sekere beenmurgareas en limfoiede weefsels. Ongelukkig is dit nie bekend hoeveel van die liggaam bedek moet word om ' $n$ individu tot so 'n mate te beskerm dat hy die bestraling sal oorleef nie.

'n Nuwe ontwikkeling wat nou nog bygekom het, is die ontwikkeling van die Neutronbom. Sy verwoestende krag werk nie deur drukgolf en hittebestraling nie maar deur 'n meer intense, onsigbare, deur alle materiaal dringende dodelike bestraling, wat alle biologiese lewe vernietig.

Die belang van hierdie gesondheidsprobleem word besef as daar gekyk word na die oorlogs-voorsorgmaatreëls wat deur ander lande getref word, terwyl die program in SuidAfrika min ondersteuning kry en selfs bevraagteken kan word.

Bykomend tot die burgerlike beskermingsmaatreëls wat in die land getref word, moet Suid-Afrika ook oor die vermoë beskik om trauma in vredestyd te kan hanteer en ook gedurende enige toekomstige nasionale krisis. Dit kan gedoen word deur middel van opleidingsprogramme in traumatologie vir die publiek sowel as protessionele gesondheidspersoneel. Na my mening word daar te min aandag gegee aan opleiding in traumatologie.

\section{Motorongelukke}

Motorongelukke bly nog steeds dié groot oorsaak van baie beserings en sterfgevalle. Die volgende statistieke is verkry van die Nasionale Verkeersveiligheidsraad:

\begin{tabular}{|l|r|r|r|r|r|}
\hline JAARTAL & \multicolumn{1}{|c|}{1973} & 1974 & \multicolumn{1}{|c|}{1975} & 1976 & 1977 \\
\hline Sterfgevalle & 8580 & 6344 & 8124 & 8030 & 6420 \\
Emstige beserings & 19375 & 16274 & 20690 & 20693 & 19879 \\
Geringe beserings & 45601 & 39928 & 47605 & 48755 & 49882 \\
\hline
\end{tabular}

Hierdie statistiek sluit alle rassegroepe in. Gedurende 1977 het die sterfgevalle op die Suid-Afrikaanse paaie aansienlik gedaal, die emstige beserings toon ook 'n daling terwyl die geringe beserings toegeneem het. Hierdie verandering kan moontlik toegeskryf word aan die spoedbeperkings wat ingestel is om brandstof te bespaar. Volgens inligting van die Nasionale Verkeersveiligheidsraad is daar nog nie voldoende bewys gelewer dat die verpligte dra van veiligheidsgordels in passasiersmotors enige merkbare verandering aan bogenoemde statistiek sal meebring nie. Dit wil voorkom asof daar geen bevredigende metode bestaan om motorvoertuigongelukke te voorkom nie. Daar moet strenger maatreëls bepaal word waaraan bestuurders moet voldoen alvorens hul 'n bestuurderslisensie kan bekom.

Soos reeds genoem is daar op die gebied van die chirurgie en verwante dissiplines in die post-trauma fase - veral in noodbehandeling, behandeling daarna en in rehabilitasie merkbare vordering gemaak - maar as daar gekyk word na die pre-trauma fase en die beseringsfase, veral by motorvoertuigongelukke, kan die probleem duidelik waargeneem word dat daar op hierdie gebied maar min vordering gemaak is. 
Die pandemiese aard van ongeluksbeserings regverdig 'n openbare gesondheidsbenadering op 'n nasionale vlak. Lewensverlies- en ongeskiktheidsyfers is hoër as by enige ander enkele oorsaak

In baie lande het departemente of rade wat gemoeid is met verkeersveiligheid 'n groot aantal maatreëls daargestel ter beveiliging van die land se paaie. So is daar in Suid-Afrika ook dikwels strenge maatreëls wat toegepas word om bestuurders wat onder die invloed van alkohol bestuur aan te keer. Hierdie maatreëls kos die land baie geld. Die dra van veiligheidsgordels in ' $n$ motor het verpligtend geword. Alhoewel sterftes in motorvoertuigongelukke afgeneem het, is die sterftes op Suid-Afrikaanse paaie nog onrusbarend hoog. Dus is die dra van veiligheidsgordels nog nie die aangewese maatreël nie. Vir motorfietsryers is die dra van veiligheidshelmets wetlik afdwingbaar. Die motorvervaardigers moet ook aan sekere spesifieke veiligheidsvereistes voldoen by die bou van motorvoertuie. Verkeersregulasies is uitgevaardig. Bogenoemde maatreëls is maar 'n paar maatreëls wat teoreties en prakties moontlik is om beserings wat deur padongelukke veroorsaak word, te verminder

Dikwels gebeur dit dat wanneer twee voertuie bots dit onmiddellik na die botsing aan die brand slaan met ernstige brandwonde of sterftes tot gevolg.

Dit is ' $n$ probleem wat al jare voorkom en grootliks voorkombaar is deur bepalings dat alle motors botsing-weerstand petroltenks moet hê.

Indien 'n vliegtuig op die aanloopbaan met 'n paal bots sal daar dadelik intensief ondersoek ingestel word oor wat die paal daar doen en wie dit daar geplaas het. Tog kan dieselfde vrae gevra word oor die honderde pale wat langs ons duisende kilometers openbare paaie aangebring is. Aandag moet hieraan gegee word

Tans word daar baie aandag gevestig op motorongelukke as die hoofoorsaak van sterftes en ernstige beserings. Tog is hierdie maar net 'n spektrum van moontlike oorsake van beserings wat fataal of baie ernstig kan wees. By motorongelukke is die grootste getal pasiënte tussen die ouderdom van 10 tot 30 jaar. alhoewel die ouderdomme van die beseerdes wissel van 1 jaar tot 90 jaar.

\section{Huishoudelik}

Die gebrek aan voldoende beheer in die hantering van nuwe toksiese chemikalieë asook die hantering van daardie chemikalieë wat in elke huishouding gevind word lei té dikwels tot vergiftigings.

Die sintetiese materiale wat vir klere en meubels gebruik word is dikwels hoogs ontvlambaar en is dikwels betrokke in die hoë persentasie brandwonde wat voorkom. Klere wat van ' $n$ sintetiese materiaal vervaardig is, is ' $n$ voldwonge gevaar as dit aan enige bron van vuur blootgestel is. Sterfgevalle wat voorkom by tuisbrande word in die meeste gevalle moontlik veroorsaak deur toksiese dampe wat deur die brandende sintetiese matte, matrasse en gordyne vrygestel word. Plas- tiese meubelment in die huis is nog 'n bron van gevaar by brande.

K. Salheim, 'n navorser van Oslo, Noorweë wat navorsing gedoen het oor beserings wat tot sterftes gelei het, het bevind dat beserings wat veroorsaak is deur ' $n$ val in die huis die algemeenste oorsaak was wat tot sterftes gelei het. Motorvoertuigongelukke was kort op eersgenoemde se hakke. Die navorser het ook bevind dat meer as $40 \%$ beseerdes binne 24 uur na besering opgedoen is, sterf. Dit is dus ' $n$ aanduiding dat by beseerdes diagnostiese- en terapeutiese maatreëls vroeër begin moet word.

Meer as $40 \%$ sterfgevalle kom voor na een week na besering opgedoen is wat dan ook aandui dat komplikasies algemeen voorkom. Inteendeel, in sy verslag dui die navorser aan dat $55 \%$ van sterfgevalle voorgekom het as gevolg van komplikasies wat ingetree het. Baie komplikasies kan voorkom word deur die toepassing van moderne beginsels in die behandeling van die beseerde. Onvoldoende respirasie en bloeding is die twee hoofoorsake van sterftes.

Ander navorsing wat gedoen is oor die oorsake van besering plaas ongelukke by die huis as die tweede grootste oorsaak van beserings en sterftes. Hierdie ongelukke tuis kan die volgende insluit: Kinders wat uit wiegies, beddens en stootwaentjies val, mense wat van lere en trappe af val, mense gly op nat vloere, val oor 'n mat of tapyt, snywonde, brandwonde, beserings wat in die tuin opgedoen word. Persone wat in hierdie kategorie val se ouderdom is of baie jonk of 'n bejaarde. Meestal onder die ouderdom van 10 jaar en bo die ouderdom van 70 jaar.

\section{Sport}

Sport word beskou as die derde grootste oorsaak van beserings. Oorsake by hierdie kategorie is kontaksport, soos byvoorbeeld rugby, boks, sokker ensomeer. Alle sportsoorte kan egter hier benoem word. Meer gevaarlike sportsoorte is die oorsaak van meer beserings, byvoorbeeld perdry, valskermspringers. Dan is daar ook nog kinders wat van swaaie, glyplanke en klouterrame af val. By die beoefening van enige sportsoort kan beserings opgedoen word. Baie van die jonger kinders word beseer terwyl hulle speel.

\section{Alkoholmisbruik}

Alkoholmisbruik en aanrandings word beskou as die vierde grootste oorsake van beserings.

\section{Nywerhede}

'n Mens se werk of beroep word beskou as die vyfde groot oorsaak van beserings. Gedurende die afgelope jare het die nywerhede baie klem geplaas op die voorkoming van beserings en is veral aandag geskenk aan veilige gereedskap en veilige werkmetodes.

Volgens beskikbare statistiek was daar in 19742522 sterfgevalle en 33676 ernstige beserings opgedoen in ongelukke wat by die werk voorgekom het. 
Die voorsiening wat nywerhede maak vir die behandeling van die beseerde werksman varieer vanaf die bemande noodhulpkassıe in die werksgebied tot komprehensiewe ongevalle en rehabilitasiedienste. Die nywerheidsgesondheidsdienste is ' $n$ vertakking van voorkomende gesondheidsdienste. Die belangrikste faktor in hierdie dienste is daarop gemik om 'n gesonde werksman in 'n gesonde en veilige omgewing te hou.

\section{VOORKOMENDE MAATREËLS}

Net soos daar baie spesifieke beserings is tot verhouding van 'n wye verskeidenheid van omstandighede, mense en omgewing, net so is daar ook voldoende en baie verskeie maatreëls, strategie en metodes om beserings te verminder. Dit is logies dat voldoende voorkomende maatreëls om beserings te verminder veel meer inhou as slegs enkele maatreëls. Dit geld selfs vir 'n spesifieke kategorie besering. Indien die daaglikse omvang van besering en die implikasies daarvan in ag geneem word is dit as benadering volkome geregverdig.

Dit is me altyd 'n maklike taak om die beskikbare faktore wat as voorkomende maatreëls gebruik kan word te identifiseer nie. Meestal word voorkeur gegee aan maatreëls wat daarop gemik is om verandering van gedrag in die individu in die gemeenskap te weeg te bring. Gelykstaande hieraan moet voorkeur ook gegee word aan maatreëls om gevare in die omgewing te verminder.

Daar is twee benaderings tot die voorkoming van beserings, naamlik: die aktiewe benadering waar van die individu verwag word om sy bydrae te lewer ter voorkoming van beserings, en die passiewe benadering waar daar outomaties te werk gegaan word om mense en hul besittings te beskerm. In die voorkomende gesondheidsdienste is dit duidelik dat hierdie aktiewe en passiewe benadering nagestreef word. Tog blyk dit dat 'n passiewe benadering, waar daar nie op die samewerking van die individu staat gemaak word nie, dalk nog die beste voorkomende maatreëls sal wees

\section{SLOT}

Daar is ook ' $n$ behoefte aan meer fundamentele navorsing op die fisiologiese reaksies van trauma. Die waarde van navorsing wat deur bekwame praktisyns op hierdie gebied gedoen word moet besef word en diegene wat om hulp genader word moet hul samewerking gee. Die uitslae van sulke studies en die analise daarvan mag lei tot waardevolle kennis in die behandeling van trauma in die mens.

Die mens is uniek en nuwe bevindinge wat met laboratoriese eksperimente op diere uitgevoer word kan in baie gevalle nie op die mens toegepas word nie. Daar is by voorbeeld geen bewyse dat enige bekende dier vatbaar is vir hepatitis soos dit in die mens gevind word nie. Waar dit voorkom of die behandeling van die beseerde onvoldoende is, moet verbeterde metodes gevind word, nie alleenlik om die belange van die pasiënt te beskerm nie maar ook om kliniese menslike studies moontlik te maak.

Navorsing in hospitale en trauma-senters bied unieke moontlikhede om die mens se kennis aangaande die behandeling van ernstig beseerde pasiënte te verbeter. Hierdie studies kan aanleiding gee tot verbeterde behandeling van pasiënte en dus ook pasiënt-oorlewing. 'n Status quo benadering tot hierdie gesondheidsprobleem sal die mortaliteit nie verlaag nie.

Trauma bly steeds die hoofoorsaak van sterfgevalle, verminking en gestremdheid by die mens onder 37 -jarige ouderdom. Oor lang naweke en skoolvakansietye kan trauma as gevolg van ongelukke op baie gebiede byna endemiese status aanneem, in Suid-Afrika en in die wye wêreld. Die oorsake van trauma is meestal mensgemaakte oorsake, behalwe in die geval van natuurlike rampe. Tot 'n groot mate moet trauma voorkombaar wees as die mens dit as prioriteit beskou en die nodige aandag daaraan gee wat dit toekom. Die voorkoming van trauma en die behandeling daarvan kan as minderwaardig geklassifiseer word as al die gesondheidsprobleme in aanmerking geneem word.

Daar is gepoog om aan te dui dat dieselfde professionele doelwitte wat die hoeksteen is van die gesondheidsdienste oor baie eeue, ook essensiëel is in al die aspekte van die trauma-gebied. Daar moet voortgegaan word om deeglik en sistematies, sonder tradisionele voorkeure, die maatreëls te identifiseer wat nodig is om verliese in die gemeenskap en beserings aan die mense te voorkom. Hierdie maatreëls ter voorkoming van beserings moet so effektief en so spoedig as moontlik toegepas word.

Met talle ondersoeke is gevind dat die meeste ongelukke voorgekom het as gevolg van onverskilligheid en dat eenvoudige voorsorgmaatreëls die meeste ongelukke kon voorkom het

Ongelukke kan lei tot vroeë dood as gevolg van die beserings wat opgedoen is, of dit mag lei tot potensiële fatale komplikasies. Voldoende behandeling van die beseerde by die ongelukstoneel en gedurende vervoer na die hospitaal kan baie lewens red. $20 \%$ van beseerde pasiënte wat in hospitale sterf se lewens kon moontlik gered gewees het as meer noukeurige aandag gegee was aan voldoende ventilasie en die diagnosering en beheer oor bloeding

\section{BIBLIOGRAFIE}

1. Cameron, J. D. Accident services today, Injury, The British Joumal of Accident Surgery, 1972, Vol. 3, No. 4, pp. 261-264.

2. Galasker, C. S. B., Edwards, D. H. The causes of injuries requiring admission to hospital in the 1970s, Injury. The British Journal of Accident Surgery, Vol. 6 , No. 2, pp. 107-112.

3. Haddan, W. The second annual William, S. Stone lecture of the American Trauma society, The Journal of Trauma, 1978, Vol. 18, No. 9, pp. 651-656. Morgan, T. H. Accident services today, Injury, The British Journal of Accident Surgery, Vol. 4, No. 2, pp. 95-101

5. Scott, J. C. Accident services today, Injury. The British Joumal of Accident Surgery, 1972, Vol. 3, No. 3, pp. 146-147.

6. Smith, H. P. R. Time to die from injuries received in road traffic accidents, Injury, The British Joumal of Accident Surgery, 1970, Vol. 2, No. 2. pp. 99- 102

7. Solheim, K. Fatal injuries, Injury. The British Joumal of Accident Surgery, 1971, Vol. 3, No. 2, pp. 93-99.

8. Stone, W. S. Trauma: A continuing U.S. Health problem, The Journal of Trauma, 1977, Vol. 17, No. 2, pp. 89-92

9. Voorligtingspamflet Nr. 2. Padongelukke, Die Nasionale Raad vir die versorging van kreupeles in Suid-Afrika, 1963. 